\title{
Analisa Biaya Penanganan Berdasarkan Penilaian Kondisi Jalan dengan Metode Road Condition Index (RCI) pada Ruas Jalan Hertasning
}

\author{
St. Fauziah Badaron ${ }^{1}$, Watono ${ }^{2}$, Suriati Abd. Muin ${ }^{3}$, M. Rheza C.A ${ }^{4}$, Darmawansyah Firdaus ${ }^{5}$ \\ 1,2,3,5,5 Teknik Sipil, Universitas Muslim Indonesia, Makassar, Indonesia \\ Email: ${ }^{1}$ sitifauziahbadrun@gmail.com, ${ }^{2}$ Watono.watono@umi.ac.id, ${ }^{3}$ Ssuriati.abdmuin@umi.ac.id, ${ }^{4}$ Echag9@gmail.com, ${ }^{5}$ AnchaFirdaus99@gmail.com
}

\begin{tabular}{|c|c|}
\hline & Abstrak \\
\hline $\begin{array}{l}\text { Kata Kunci } \\
\text { Penilaian Kondisi } \\
\text { Jalan; RCI; } \\
\text { Pemeliharaan Jalan . }\end{array}$ & $\begin{array}{l}\text { Ruas jalan Hertasning merupakan jalur strategis yang menghubungkan kawasan industri } \\
\text { di antara dua Kabupaten / Kota yaitu Makassar dan Gowa. Tingginya frekuensi kendaraan } \\
\text { yang lewat di atas permukaan jalan yang ada menyebabkan turunnya tingkat pelayanan jalan. } \\
\text { Penelitian ini bertujuan untuk mengetahui jenis kerusakan dan nilai kondisi yang terjadi } \\
\text { dengan menggunakan metode Road Condition Index (RCI), juga untuk menentukan jenis } \\
\text { penanganan yang tepat serta mengetahui biaya dan penanganan terhadap kerusakan jalan } \\
\text { pada ruas Jalan Hertasning. Analisis data dilakukan perhitungan kondisi fungsional dengan } 2 \\
\text { tahap perhitungan yaitu metode Road Condition Index (RCI) dan analisis anggaran biaya dari } \\
\text { hasil penilaian RCI dengan metode standar Bina Marga 1995. Hasil dari penelitian ini } \\
\text { ditemukan bahwa jenis kerusakan pada ruas Jalan Hertasning antara lain pelepasan butir, } \\
\text { lubang, lubang bekas galian utilita, tambalan dan retak kulit buay juga mendapatkan nilai } \\
\text { rata - rata RCI sebesar } 76,92 \text { dan juga penanganan serta biaya yang digunakan menggunakan } \\
\text { AHSP Bina Marga } 2018 \text { membutuhkan sebesar Rp. 531.210.000,-. Dengan adanya penelitian } \\
\text { kondisi jalan yang menggunakan metode RCI dapat memberikan gambaran atau dekripsi } \\
\text { tentang kondisi jalan di Jalan Hertasning, yang dapat digunakan sebagai data base untuk } \\
\text { perencanaan dan pelaksanaan rehabilitasi dan pemeliharaan jalan. }\end{array}$ \\
\hline $\begin{array}{l}\text { Keywords } \\
\text { Road Condition } \\
\text { Assessment; RCI; } \\
\text { Road } \\
\text { Maintenances. }\end{array}$ & $\begin{array}{l}\text { Abstract } \\
\text { The Hertasning road is a strategic route that connects the industrial estate between two } \\
\text { Regencies / Cities, namely Makassar and Gowa. The high frequency of vehicles passing over } \\
\text { the existing road surface causes a decrease in the level of road service. This study aims to } \\
\text { determine the type of damage and the value of conditions that occur using the Road } \\
\text { Condition Index (RCI) method, also to determine the appropriate type of treatment and } \\
\text { determine the cost and treatment of road damage on the Hertasning Road section. Data } \\
\text { analysis was performed functional condition calculations with } 2 \text { stages of calculation, namely } \\
\text { the Road Condition Index (RCI) method and the analysis of the cost budget from the RCI } \\
\text { assessment results with the } 1995 \text { Bina Marga standard method. The results of this study found } \\
\text { that the types of damage to the Hertasning Road section included grain release, holes, utility } \\
\text { pit excavations, patches and crocodile cracks also received an average RCI of 76.92 and also } \\
\text { the handling and costs used using AHSP Bina Marga } 2018 \text { requires Rp. } 531,210,000 \text {. With } \\
\text { the research on road condition assessment using the RCI method can provide an overview or } \\
\text { decryption of road conditions on Hertasning Road, which can be used as a data base for } \\
\text { planning and implementing road rehabilitation and maintenance. }\end{array}$ \\
\hline
\end{tabular}

\section{PENDAHULUAN}

Transportasi mempunyai peranan penting dalam kehidupan manusia, karena tranportasi mempunyai pengaruh besar terhadap perorangan, masyarakat, pembangunan ekonomi, dan sosial suatu negara (Natsir, 2016). Pembangunan atau pengembangan sarana transportasi juga dapat menimbulkan dampak positif terhadap suatu wilayah (Fisu, 2018). Menurut Humang (2016), pembangunan sarana transportasi memiliki hubungan timbal balik dengan perekonomian suatu daerah untuk menunjang perkembangan kawasan perkotaan dan pedesaan. Perkembangan transportasi yang pesat secara tidak langsung akan memperbesar resiko tumbuhnya permasalahan lalu lintas (Fisu, 2019). Tingginya frekuensi kendaraan yang melintas di atas permukaan jalan yang ada menyebabkan turunnya tingkat pelayanan jalan. Karena pada umumnya jalanjalan dalam kota jarang dilewati kendaraan berat, maka penurunan tingkat pelayanan dapat berupa kerusakan pada permukaan jalan. Adanya retak-retak (crack), pengelupasan (ravelling) dan lubang-lubang (potholes) pada permukaan jalan merupakan bukti bahwa jalan mengalami penurunan tingkat pelayanan atau jalan 
dalam kondisi rusak. Kerusakan-kerusakan kecil yang tidak segera diantisipasi penanganannya menyebabkan kerusakan yang terjadi semakin parah, pengaruhnya semakin luas serta mengurangi kapasitas jalan itu sendiri.

Perbaikan konstruksi jalan raya merupakan serangkaian kegiatan yang diarahkan untuk menjaga agar struktur dan jalan raya dapat berfungsi senyaman mungkin. Perbaikan jalan raya ini perlu dilaksanakan mengingat sebagian struktur perkerasan jalan tidak dapat selalu rata selama umur rencananya tanpa adanya kerusakan-kerusakan. Ada masa dimana keadaan perkerasan jalan mulai memburuk hingga pada tingkat yang tidak layak. Usaha melakukan perbaikan-perbaikan dengan tujuan untuk mempertahankan tingkat layanan selama umur rencana biasa disebut dengan pekerjaan pemeliharaan jalan. Untuk mengetahui penanganan yang tepat serta untuk mengetahui biaya pemeliharaan dan peningkatan pada ruas jalan Hertasing maka penulis membuat tulisan ilmiah ini.

Maksud dari penulisan ini adalah untuk mengetahui biaya penanganan terhadap kerusakan pada ruas jalan Hertasing. Adapun tujuan penulisan ini adalah untuk mengetahui jenis kerusakan dan nilai kondisi yang terjadi pada ruas Jalan Hertasning dengan menggunakan metode Road Condition Index (RCI), menentukan jenis penanganan yang tepat pada ruas Jalan Hertasning dengan menggunakan metode Road Condition Index (RCI) serta mengetahui biaya serta penanganan terhadap kerusakan jalan ruas Jalan hertasning. Dalam penilaian dan penangan kondisi jalan ruas jalan Hertasning, penulis membatasi penulisan ini dengan pada hal berikut: (1) Lokasi penelitian yaitu pada ruas dengan perkerasan lentur 4 lajur dan 2 jalur jalan Hertasning sepanjang $1.1 \mathrm{Km}$ dimulai dari depan Gedung kantor DPRD sampai dengan Rumah sakit Grestelina, (2) Kondisi jalan di analisis dengan metode RCI, dan (2) Data sekunder lalu lintas dan analisa harga satuan biaya didapatkan dari dinas Bina Marga Prov. Sulsel.

\section{METODE PENELITIAN}

\subsection{Teknik Pengumpulan dan Analisis Data}

Dalam Penelitian ini, teknik pengumpulan data dilakukan dengan cara mencari keterangan yang bersifat primer maupun sekunder yang nantinya dipakai sebagai bahan penelitian. Data primer berupa data Jenis kerusakan Jalan, Kondisi Utilitas Jalan, Dimensi kerusakan jalan dan tingkat kekasaran jalan diperoleh dengan melakukan survey sedangkan data sekunder diperoleh dari dinas-dinas maupun instansi-instansi terkait. Adapun data sekunder yang dibutuhkan yaitu: Peta lokasi penelitian, Kondisi Utilitas Jalan, Daftar Analisa Harga Satuan Bina Marga Serta daftar harga dan upah dari pemerintah kota makassar.

Berikut adalah Teknik pengumpulan data berdasarkan masing-masing metode beserta analisis data untuk menjawab rumusan masalah:

Penilaian kondisi jalan sesuai Metode Road Condition Index (RCI)

Nilai RCI diambil dari hasil pemeriksaan kondisi jalan secara visual yang sama dengan metode SDI tetapi dengan parameter berbeda sesuai dengan identifikasi kerusakan RCI.

Cara mengukur luas kerusakan adalah sebagai berikut, daerah yang rusak terlebih dahulu ditandai dengan cat atau kapur untuk menandai batas-batas pengukuran dengan dengan membuat garis segi empat panjang dengan dua sisi segi empat dibuat minimum berjarak $10 \mathrm{~cm}$ dari daerah kerusakan. Adapun alat yang di butukan pada pelaksanaan survey dengan metode SDI yaitu pilox atau cat, meteran, kertas dan alat tulis dan rompi pengaman.

Selanjutnya menentukan nilai RCI, Tahapan penentuan nilai RCI adalah sebagai berikut:

- Pegukuran kuantitas jenis kerusakan

- Menentukan tingkat kerusakan jalan yaitu biasa (low), sedang (medium),parah (hight);

- Menentukan kadar kerusakan (density)

- Menentukan nilai pengurang (deduct value)

- Menentukan total deduct value (TDV)

- Menentukan corrected deduct value (CDV).

- Menentukan nilai RCI

- Menentukan jenis penanganan

Analisa anggaran biaya dengan menggunakan Analisa bina marga tahun 2018 dengan menggunakan standar harga harga bahan yang dikeluarkan oleh Pemerintah Kota Makassar. 


\subsection{Bagan Alir Penelitian}

Tahapan penelitian dilakukan dengan melakukan studi pustaka berdasarkan penelitian terdahulu dan didasari dengan referensi serta literatur. Pengumpulan data berupa data primer maupun data sekunder dilakukan setelah studi pustaka selesai. Tahapan penelitian disajikan pada gambar 1.

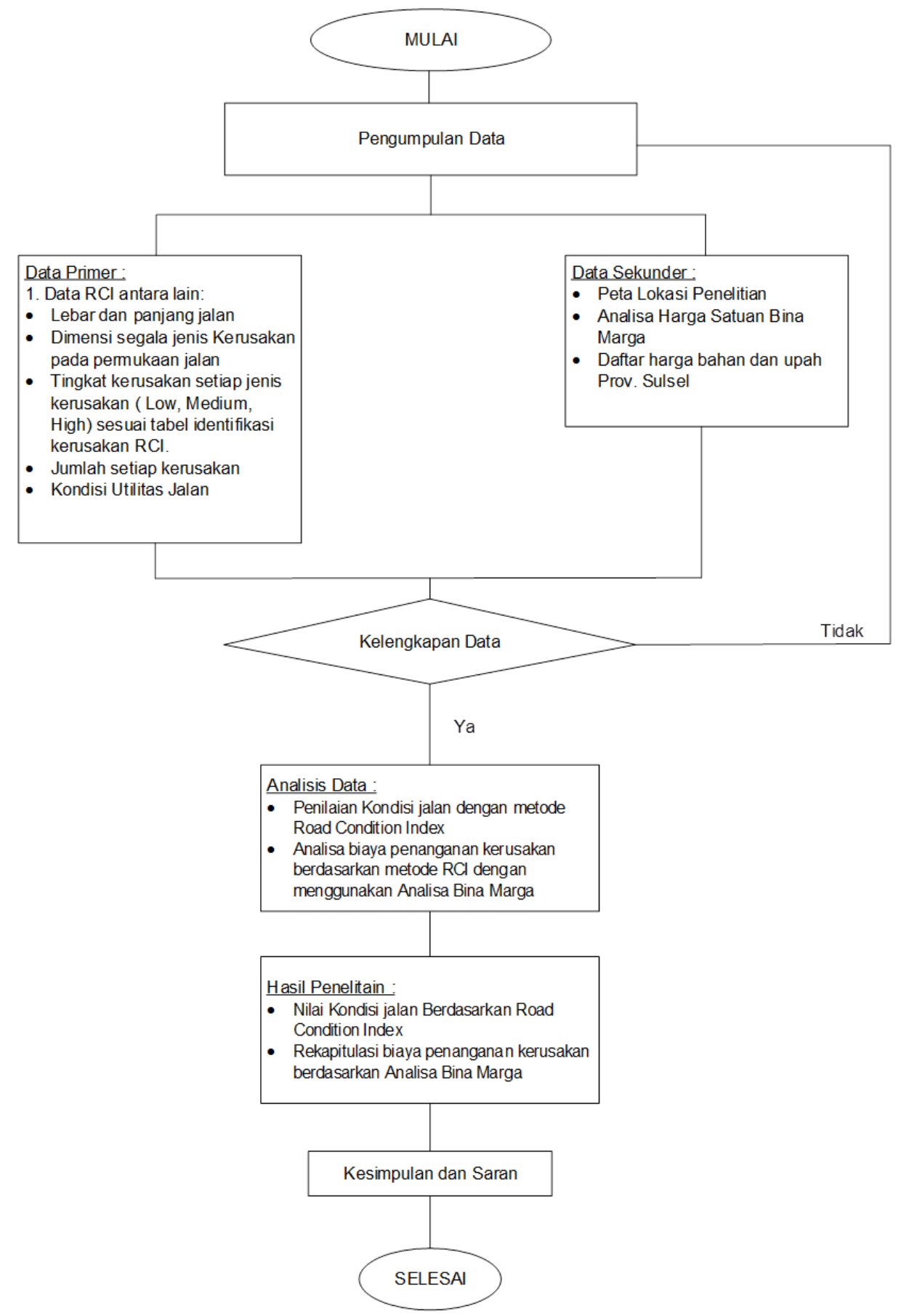

\section{HASIL DAN PEMBAHASAN}

Gambar 1. Bagan Alir Penelitian

Berdasarkan permasalahan dan metode penelitian yang dikemukakan, maka diperoleh data dari hasil survei selanjutnya dilakukan pembahasan sehingga dapat diidentifikasikan jenis dan tingkat kerusakan sesuai dengan kondisi jalan pada Ruas Jalan Hertasning mulai dari Pertigaan Jalan AP. Pettarani (Samping Gedung DPRD Kota Makassar) Sampai depan RS. Hasil penelitian yang diperoleh berupa data-data kondisi jalan 
dengan cara pengumpulan data survei visual yaitu kategori kerusakan jalan, ukuran dan persentase kerusakan jalan.

\subsection{Kondisi Terkini Jalan dan Inventarisasi Kerusakan Jalan}

Ruas Jalan Hertasning merupakan jalan Arteri dengan kelas jalan I, melayani arus lalu lintas 2 arah, dan nilai LHR sebesar $21.000 \mathrm{smp} /$ hari. Survey visual kondisi permukaan perkerasan jalan dilakukan untuk tiap Jalur.

Lapisan permukaan jalan pada ruas Hertasning mulai dari Pertigaan Jalan AP. Pettarani (Samping Gedung DPRD Kota Makassar) Sampai depan RS yaitu dengan lapis permukan jalan AC (asphalt concrete) yang terdiri dari 2 Jalur 4 lajur jalan. Dan masing masing jalur memiliki lebar 8 meter.

\subsection{Penilaian Kondisi Jalan Berdasarkan Metode RCI}

Berdasarkan pada spesifikasi penialain kondisi jalan dengan metode RCI dan Hasil Survei Inventarisasi Kerusakan maka diperoleh data kerusakan diambil Ruas Jalan Hertasning mulai dari Pertigaan Jalan AP. Pettarani (Samping Gedung DPRD Kota Makassar) Sampai depan RS. Grestelina yang berjarak $1.1 \mathrm{Km}$ dengan mengambil contoh STA 0+000 - 0+100. sebagai berikut:

Tabel 1. Tabel Inventarisasi Kerusakan STA 00+000 - 00+100

\begin{tabular}{|c|c|c|c|c|c|c|}
\hline \multirow[b]{2}{*}{ STA } & \multirow[b]{2}{*}{ JENIS KERUSAKAN } & \multirow[b]{2}{*}{$\boldsymbol{\Sigma}$} & \multicolumn{3}{|c|}{ UKURAN MASING-MASING KERUSAKAN (m) } & \multirow[b]{2}{*}{$\begin{array}{c}\text { KELAS } \\
\text { KERUSAKAN }\end{array}$} \\
\hline & & & $\mathbf{P}$ & $\mathbf{L}$ & A & \\
\hline \multirow{4}{*}{$\begin{array}{l}8 \\
\\
+ \\
\vdots \\
8 \\
8 \\
+ \\
+\end{array}$} & Retak Kulit Buaya & 1 & 8 & 2 & 16.00 & $M$ \\
\hline & Lubang Galian Utilitas & 1 & 1.1 & 8 & 8.80 & $\mathrm{H}$ \\
\hline & Lubang & 1 & 0.8 & 0.85 & 0.68 & M \\
\hline & \multicolumn{2}{|l|}{$\mathbf{n}=$} & & & & \\
\hline
\end{tabular}

A. Menentukan Kelas Kerusakan

Berdasarkan data kerusakan diatas maka, Ruas Jalan Hertasning STA 0+000+0+100 dapat digolongkan berdasarkan tingkatan sesuai dengan table 2.7. dan dapat dilihat dari data tabel berikut

Tabel 2. Tabel identifikasi kelas Kerusakan STA 0+000-0+100

\begin{tabular}{|c|c|l|}
\hline Jenis Kerusakan & $\begin{array}{c}\text { Kelas } \\
\text { Kerusakan }\end{array}$ & \multicolumn{1}{c|}{ Identifikasi Kerusakan } \\
\hline \hline Retak & $\mathrm{M}$ & $\begin{array}{l}\text { Retak kulit buaya ringan terus berkembang ke dalam pola } \\
\text { atau jaringan retakan yang diikuti gompal ringan }\end{array}$ \\
\hline $\begin{array}{c}\text { Lubang Bekas Galian } \\
\text { Utilitas }\end{array}$ & $\mathrm{H}$ & $\begin{array}{l}\text { Kedalaman maksimum }>1-2 \mathrm{in} .(25.4-50.8 \mathrm{~mm}), \text { diameter } \\
\text { rata-rata 18-30 in }(457-762 \mathrm{~mm})\end{array}$ \\
\hline Lubang & $\mathrm{M}$ & $\begin{array}{l}\text { Kedalaman maksimum }>1 / 2-1 \mathrm{in} .(12,7-25,4 \mathrm{~mm}), \\
\text { diameter rata-rata } 18-30 \text { in }(457-762 \mathrm{~mm})\end{array}$ \\
\hline
\end{tabular}

B. Menentukan densitas kerusakan

Densitas $(\%)=($ Luas Kerusakan/Luas Perkerasan $) \times 100 \%$
a) $\operatorname{Retak}=\frac{16.00}{8 \times 100} \times 100 \%=0.020 \%$
b) Raveling $=\frac{8.8}{8 \times 100} \times 100 \%=0.011 \%$
c) Lubang $=\frac{0.68}{8 \times 100} \times 100 \%=0.001 \%$

C. Mencari Deduct Value (Dv)

Untuk menghitung Deduct Value dengan memasukkan hasil presentase densitas kedalam grafik DV, dengan menarik garis vertikal hasil prosentase densitas sampai memotong tingkat kerusakan. Misalnya jenis kerusakan alur berikut: 


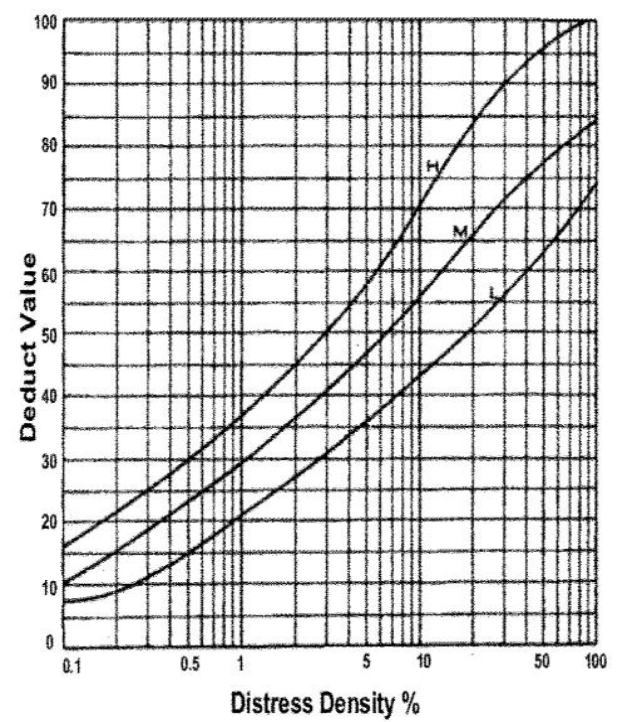

Gambar 2. Grafik Deduct Value

Dengan nilai densitas $=0.020$, dan tingkat kerusakan Medium maka berasarkan grafik diatas maka di dapatkan DV $=10$.

D. Menghitung Tdv

TDV didapatkan dari menjumlahkan hasil dv pada setiap STA.

Tabel 3. Tabel Perhitungan Total Deduct Value

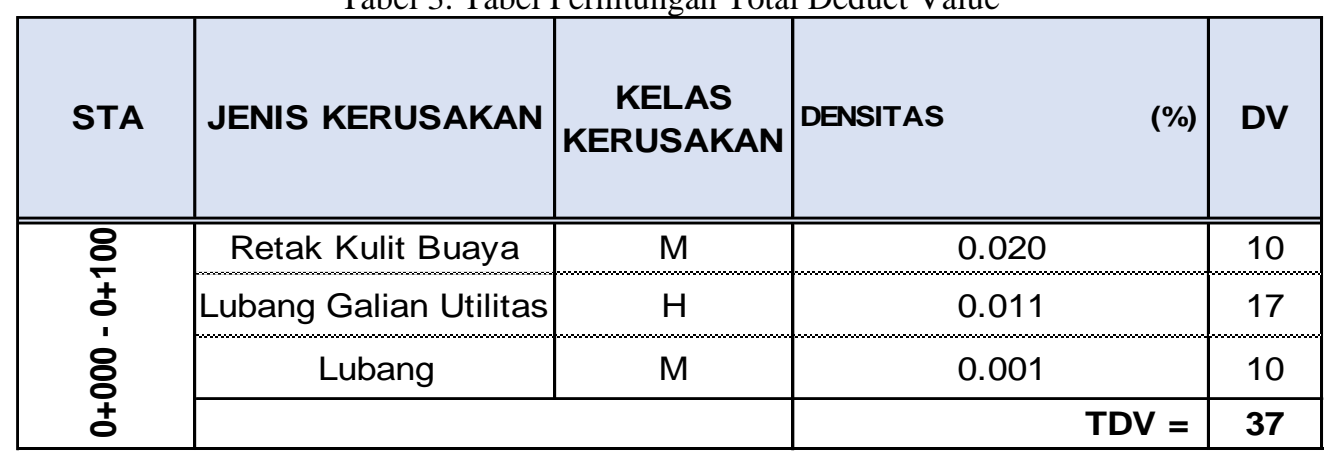

E. Menghitung CDV

CDV dihitung dengan memasukkan nilai TDV ke dalam garfik CDV, dengan cara menarik garis vertical TDV sampai memotong garis $\mathrm{n}$ kemudian ditarik garis horizontal. Jumlah rata-rata kerusakan per segmen (n) $=1$, Nilai $\mathrm{TDV}=37$.

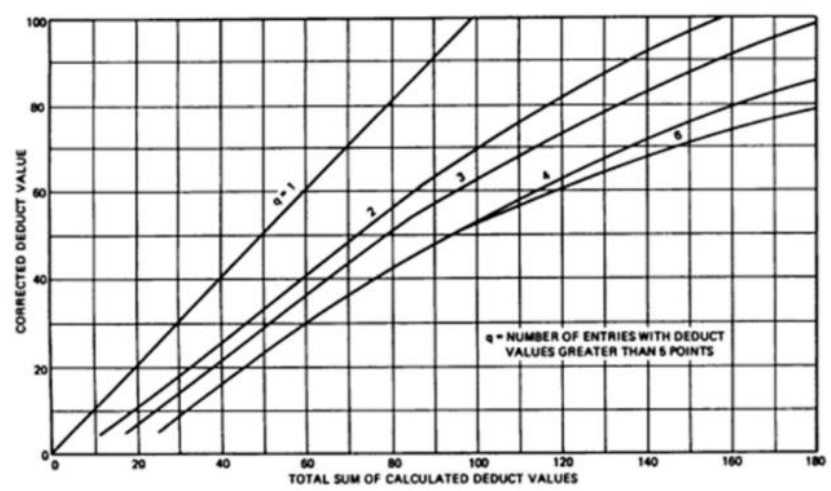

Gambar 3. Grafik Deduct Value 
F. Menghitung nilai kondisi perkerasan (RCI)

$$
\begin{aligned}
\mathrm{RCI} & =100-\mathrm{CDV} \\
\mathrm{RCI} & =100-37 \\
& =63
\end{aligned}
$$

G. Menghitung nilai kondisi perkerasan (RCI)

Dari nilai RCI yang didapatkan tingkat kerusakan jalan dapat dinilai dengan menggunakan grafik penilaian dibawah ini.

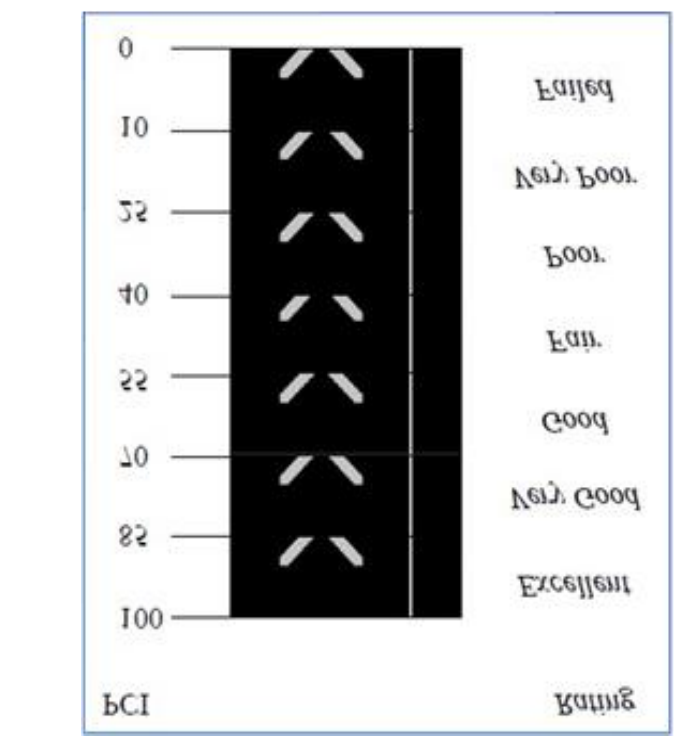

Gambar 4. Rating kondisi perkerasan berdasarkan nilai RCI

H. Menilai kondisi jalan berdasarkan nilai RCI

Berdasarkan hasil evaluasi penilaian kondisi jalan yang diperoleh pada segmen Ruas Jalan Hertasning STA $0+000-1+200$, maka setiap masing-masing segmen jalan dapat ditentukan pengambilan suatu keputusan untuk penentuan jenis penanganan jalan dengan hasil yang diperoleh dapat dilihat pada tabel dibawah ini.

\subsection{Kondisi Terkini Jalan dan Inventarisasi Kerusakan Jalan}

A. Jenis Pekerjaan

Berdasarkan jenis kerusakan yang terdapat di ruas jalan Hertasning maka di tentukan metode-metode perbaikan sesuai dengan AHSP Bina Marga Antara lain:
a) Galian Perkerasan Beraspal Dengan Cold Milling Machine
b) Lapis Pondasi Agregat Kelas A
c) Lapis Resap Pengikat - Aspalt Cair / Emulsi
d) Lapis Perekat - Aspalt Cair / Emulsi
e) Laston Lapis Aus Asbuton (AC-WC Asb)
f) Laston Lapis Antara Asbuton (AC-WC Asb)
g) Marka Jalan Termoplastik
h) Perbaikan Campuran Aspal Panas

B. Analisa harga satuan pekerjaan

Untuk menghitung biaya penanganan digunakan AHSP Bina Marga Tahun 2018 dan menggunakan harga standar pemerintahan setempat

\section{PENUTUP}

\subsection{Kesimpulan}

Dari hasil analisa data dan pembahasan, dapat diambil beberapa kesimpulan yakni jenis kerusakan yang dapat ditemukan pada ruas Jalan Hertasning antara lain Pelepasan Butir, Lubang, Lubang Bekas Galian Utilitas Tambalan, dan Retak Kulit Buaya serta hasil penilaian kondisi ruas jalan Hertasning dengan metode RCI (Road Condition Index) menghasilkan penilaian kondisi ruas jalan tersebut masih dalam kondisi BAIK. 
Nilai rata - rata RCI sebesar 76.92. Namun ada beberapa segmen ruas jalan memberikan hasil kemantapan jalan yang berbeda. Sedangkan dalam bentuk Persentase kerusakan diketahui bahwa metode RCI memberikan nilai kondisi jalan Sempurna 33.33 \%, Sangat Baik 16.67\%, kondisi sedang 00.00\%, Buruk 8.33 \%. Berdasarkan Hasil Penilaian Kondisi Jalan Menggunakan metode RCI, metode penangan yang diguanakan yaitu Pemeliharaan Rutin / Berkala. Jenis pemeliharaan yang dapat dilakukan untuk memperbaiki tingkat layanan jalan antara lain Pengisian retak atau Penutupan retak dengan aspal cair, Penggantian lapis permukaan dengan cara lapis perkerasan dibongkar dan kemudian dilapis kembali dengan bahan yang sama / tambalan pada lubang atau deformasi lapis permukaan, serta perataan tergantung jenis kerusakan masing-masing. Dari hasil perhitungan biaya dengan menggunkan AHSP Bina Marga 2018 dan berdasarkan penilaian penanganan kondisi jalan dengan metode RCI maka didapatkan besar biaya penangan yang di butuhkan pada ruas jalan Hertasing yaitu sebesar Rp. 531.210.000,- (Lima Ratus Tiga Puluh Satu Juta Dua Ratus Sepuluh Ribu Rupiah.

\subsection{Saran}

Dari hasil penelitian, pembahasan, dan kesimpulan yang ada maka dapat disampaikan beberapa saran untuk segala aspek yang berhubungan dengan Ruas Jalan Hertasning antara lain, (1) Perlu ketegasan dari petugas dalam melaksanakan peraturan terhadap jenis bahan dan ketebalan perkerasan yang dipakai. Perbaikan pada sistem pendukung agar kerusakan jalan tidak menjadi lebih parah. (2) Perlunya pemeliharaan rutin untuk perbaikan-perbaikan kerusakan jalan. (3) Inventarisasi data yang lebih baik bagi pihak-pihak terkait, apabila sewaktu-waktu data tersebut dibutuhkan dapat segera di pergunakan tanpa membutuhkan banyak waktu untuk mencarinya. (4) Dengan adanya penelitian penilaian kondisi jalan yang menggunakan metode RCI dapat memberikan gambaran atau dekripsi tentang kondisi jalan ini, yang dapat digunakan sebagai data base untuk perencanaan dan pelaksanaan rehabilitasi dan pemeliharaan jalan. (5) Hasil penelitian ini juga dapat sebagai bahan pertimbangan oleh tenaga ahli jalan dan stakeholder terkait untuk melaksanakan rehabilitasi dan pemeliharaan jalan secara efektif.

\section{DAFTAR PUSTAKA}

AASHTO, AASHTO Guide for Design of Pavement Structural, Washington DC: AASHTO, 1986.

Conny Meilani Putri. (2016). Studi Analisis Harga Satuan Pekerjaan Preservasi Rehabilitasi Mayor Jalan Dengan Metode Analisa Bina Marga, Yogyakarta.

Departemen Pekerjaan Umum. (2005)., Buku pedoman Teknik Pengelolaan Jalan, Jakarta

Direktorat Jenderal Bina Marga. (1983). Manual Pemeliharaan Jalan. No. 03/MN/B/1993. Direktorat Jendral Bina Marga.

Direktorat Jenderal Bina Marga. (2011). Manual Konstruksi dan Bangunan. No. 001 - 01/M/BM/2011. Survei Kondisi Jalan Untuk Pemeliharaan, Kementrian Pekerjaan Umum. Direktorat Jendral Bina Marga.

Direktorat Jenderal Bina Marga. (2011). Indonesia Integrated Road Management System (IIRMS). No. SMD-03/RC. Panduan Survei Kondisi Jalan, Kementrian Pekerjaan Umum. Direktorat Jendral Bina Marga.

Fisu AA. (2018). Analisis Lokasi pada perencanaan terminal Topoyo, Mamuju tengah. PENA TEKNIK: Jurnal Ilmiah Ilmu-ilmu Teknik 3(2) 197 - 206.

Fisu AA. (2019). Tinjauan Kecelakaan lalu Lintas Antar Wilayah Pada Jalan Trans Provinsi Sulawesi Selatan. PENA TEKNIK: Jurnal Ilmiah Ilmu-ilmu Teknik 4(1) 53 - 65.

Humang Windra Priatna \& Zulfadly. (2016). Analisis Keterpaduan Moda Transportasi Angkutan Penyeberangan Dengan Jalan Raya di Pelabuhan Bajoe Kab. Bone, PENA TEKNIK: Jurnal Ilmiah Ilmuilmu Teknik 1(1) 27 - 38.

Natsir, Rakhmawati. (2016). Karakteristik Kinerja Moda Angkutan Umum Palopo (Studi kasus penumpang Bus Executive, Suspensi Udara, Scania - PO Bintang Prima). PENA TEKNIK: Jurnal Ilmiah Ilmu-ilmu Teknik 1(2) $155-162$.

Peraturan Menteri Pekerjaan Umum Nomor 13 Tahun 2011 Tentang Tata Cara Pemeliharaan dan Penilikan Jalan. Jakarta

Pemerintah Republik Indonesia (2004), Undang-Undang Nomor 38 Tahun 2004 Tentang Jalan, Sekrestaris Negara Republik Indonesia, Jakarta.

Roaddroid, 2015, Manual Operation of Roadroid Application, Swedish.

Teknik Pelelolaan Jalan. 2005. Departemen Pekerjaan Umum Pusat Penelitian dan Pengembangan Prasarana Transportasi. JICA. 
Analisa Biaya Penanganan Berdasarkan Penilaian Kondisi Jalan dengan Metode Road Condition Index (RCI) pada Ruas Jalan Hertasning

St. Fauziah Badaron, Watono, Suriati Abd. Muin, M.Rheza C.A, Darmawansyah Firdaus

U.S. Departement of Transportation, 1982, Guidelines And Procedures For Maintenance Of Airportpavements, Faa. 